\title{
Severe pulmonary hypertension in lung disease: phenotypes and response to treatment
}

\author{
Melanie J. Brewis ${ }^{1}$, Alistair C. Church ${ }^{1}$, Martin K. Johnson ${ }^{1,2}$ and \\ Andrew J. Peacock ${ }^{1,2}$
}

Affiliations: ${ }^{1}$ Scottish Pulmonary Vascular Unit, Golden Jubilee National Hospital, Glasgow, UK. ${ }^{2}$ Both authors contributed equally.

Correspondence: Andrew Peacock, Scottish Pulmonary Vascular Unit, Level 1, Golden Jubilee National Hospital, Agamemnon Street, Glasgow, G81 4DY, UK. E-mail: apeacock@udcf.gla.ac.uk

ABSTRACT Pulmonary hypertension (PH) due to lung disease (World Health Organization (WHO) group 3) is common, but severe $\mathrm{PH}$, arbitrarily defined as mean pulmonary artery pressure $\geqslant 35 \mathrm{mmHg}$ is reported in only a small proportion. Whether these should be treated as patients in WHO group 1 (i.e. pulmonary arterial hypertension) with $\mathrm{PH}$-targeted therapies is unknown.

We compared the phenotypic characteristics and outcomes of 118 incident patients with severe $\mathrm{PH}$ and lung disease with 74 idiopathic pulmonary arterial hypertension (IPAH) patients, all treated with pulmonary vasodilators.

Lung disease patients were older, more hypoxaemic, and had lower gas transfer, worse New York Heart Association functional class and lower 6-min walking distance (6MWD) than IPAH patients. Poorer survival in those with lung disease was driven by the interstitial lung disease (ILD) cohort.

In contrast to IPAH, where significant improvements in $6 \mathrm{MWD}$ and N-terminal pro-brain natruiretic peptide (NT-proBNP) occurred, PH therapy in severe PH lung disease did not lead to improvement in $6 \mathrm{MWD}$ or functional class, but neither was deterioration seen. NT-proBNP decreased from 2200 to $1596 \mathrm{pg} \cdot \mathrm{mL}^{-1}$ ( $\left.\mathrm{p}=0.015\right)$. Response varied by lung disease phenotype, with poorer outcomes in patients with ILD and emphysema with preserved forced expiratory volume in $1 \mathrm{~s}$. Further study is required to investigate whether vasodilator therapy may delay disease progression in severe $\mathrm{PH}$ with lung disease.

@ERSpublications

Treatment of severe pulmonary hypertension associated with lung disease can improve or stabilise noninvasive outcomes http://ow.ly/Ormp1

Editorial comment in: Eur Respir J 2015; 46: 1247-1250 [DOI: 10.1183/13993003.01288-2015]

This article has supplementary material available from erj.ersjournals.com

Received: Dec 162014 | Accepted after revision: June 022015 | First published online: Aug 202015

Conflict of interest: Disclosures can be found alongside the online version of this article at erj.ersjournals.com

Part of this work has previously been published in abstract form: Brewis MJ, Church AC, Peacock A, et al. Severe pulmonary hypertension in patients with emphysema but preserved FEV1: prognosis and response to treatment. Eur Respir J 2013; 42: Suppl. 57, P2620.

Copyright $\odot$ ERS 2015 


\section{Introduction}

Mild-to-moderate pulmonary hypertension (PH) is a common complication of chronic lung disease. There is a reported prevalence of $30-70 \%$ in chronic obstructive pulmonary disease (COPD) [1-4], and $47-90 \%$ in patients with combined pulmonary fibrosis and emphysema (CPFE) syndrome $[5,6]$. The presence of $\mathrm{PH}$ is associated with poorer survival $[1,7]$. In contrast, severe $\mathrm{PH}$ (defined as mean pulmonary arterial pressure $(\mathrm{mPAP}) \geqslant 35 \mathrm{mmHg}$ ) is rare (prevalence $5-13 \%$ ), and is associated with less severe airflow obstruction but more marked hypoxaemia, impaired diffusing capacity of the lung for carbon monoxide (DLCO) and greater right ventricular dysfunction [2,3]. The development of PH in COPD has been attributed to several mechanisms, including alveolar hypoxia with resultant vasoconstriction and vascular remodelling, destruction of the pulmonary vascular bed and compression of alveolar vessels in hyperinflated emphysematous lungs. Severe $\mathrm{PH}$ has been postulated to occur in susceptible individuals with more marked hypoxic vasoconstrictive response, such as serotonin transporter gene polymorphism $[8,9]$, or possible co-existent lung and idiopathic pulmonary vascular disease. The 5th World Symposium on Pulmonary Hypertension suggested criteria for discriminating between World Health Organization group 1 (pulmonary arterial hypertension $(\mathrm{PAH})$ ) and group $3(\mathrm{PH}$ due to lung disease) disease and a classification system for patients with severe $\mathrm{PH}$ and lung disease [10].

Long-term oxygen therapy (LTOT) has been demonstrated to stabilise or decrease MPAP in COPD with mild-to-moderate PH [11-13]. However, in those with severe PH results are less encouraging [12, 14]. The role of $\mathrm{PH}$-specific medication in those with severe $\mathrm{PH}$ is uncertain. Studies to date have been of small sample sizes and included those with both mild and severe PH [15-18]. The ASPIRE (Assessing the Spectrum of Pulmonary Hypertension Identified at a Referral Centre) registry reported no survival advantage in 43 COPD patients with severe $\mathrm{PH}$ treated with pulmonary vasodilators. However, this group did demonstrate a fall in pulmonary vascular resistance (PVR) $>20 \%$ in four out of seven patients with right heart catheterisation (RHC) data, but did not evaluate clinical response by commonly used outcome measures such as 6-min walking distance $(6 \mathrm{MWD})$ or $\mathrm{N}$-terminal pro-brain natriuretic peptide (NT-proBNP) [19].

The aims of this study were to contrast and compare the survival and treatment response, defined by clinical variables such as 6MWD, NT-proBNP and New York Heart Association (NYHA) functional class in a large cohort of patients with severe $\mathrm{PH}$ associated with lung disease against a group with idiopathic PAH (IPAH), and secondly to analyse the influence of lung phenotype on outcome.

\section{Methods}

We retrospectively studied 244 treatment-naïve incident cases of precapillary PH diagnosed between January 2000 and March 2014 at the Scottish Pulmonary Vascular Unit (Glasgow, UK). Patients were referred for investigation of unexplained $\mathrm{PH}$, or $\mathrm{PH}$ felt disproportionate to the degree of lung disease and included after multidisciplinary evaluation based on RHC, echocardiography, pulmonary function testing and computed tomography (CT) of the thorax. Patients were excluded if there was incomplete RHC data, missing CT or lung function data, or an alternative aetiology for $\mathrm{PH}$.

Patients were categorised by underlying lung disease into one of four phenotypes (fig. 1): 1) emphysema with preserved forced expiratory volume in $1 \mathrm{~s}$ (FEV1) (defined as FEV1 $>80 \%$ predicted); 2) CPFE, characterised by co-existent emphysema and predominantly lower-lobe fibrosis on CT thorax, with reduced DLCO [20]; 3) interstitial lung disease (ILD); and 4) COPD, characterised by either FEV $1<60 \%$ pred or emphysema on CT with $\mathrm{FEV}_{1}<80 \%$ pred, in conjunction with an $\mathrm{FEV}_{1} /$ forced vital capacity $(\mathrm{FVC})$ ratio $<0.7$.

Only patients with severe pulmonary hypertension, defined as a mPAP $\geqslant 35 \mathrm{mmHg}$ with a pulmonary artery wedge pressure (PAWP) $\leqslant 15 \mathrm{mmHg}$ and normal or reduced cardiac output, were included. A "pure" IPAH group with neither parenchymal disease nor spirometric abnormalities was included for comparison. $\mathrm{PH}$ was defined in the IPAH group as $\mathrm{mPAP} \geqslant 25 \mathrm{mmHg}$ with a PAWP $\leqslant 15 \mathrm{mmHg}$ and normal or reduced cardiac output. Patients were excluded if they had emphysema or interstitial abnormalities of any degree on CT, or were smokers with an FEV1/FVC ratio $<0.7$ and FEV $1<80 \%$ pred.

In addition to the phenotypes described, the outcomes of patients meeting the criteria suggested by SEEGER et al. [10] were evaluated. Severe $\mathrm{PH}$ was defined as $\mathrm{mPAP} \geqslant 35 \mathrm{mmHg}$ or $\mathrm{mPAP} \geqslant 25 \mathrm{mmHg}$ with cardiac index $<2.0 \mathrm{~L} \cdot \mathrm{min}^{-1} \cdot \mathrm{m}^{-2}$ Patients were classified into two groups: 1) severe $\mathrm{PH} / \mathrm{mild}$ lung disease, defined as modest parenchymal abnormality on CT thorax, COPD with FEV $1 \geqslant 60 \%$ pred or ILD with FVC $\geqslant 70 \%$ pred; and 2) severe $\mathrm{PH} /$ severe lung disease, defined as severe $\mathrm{PH}-\mathrm{CPFE}$ (moderate-severe parenchymal abnormality), severe $\mathrm{PH}-\mathrm{COPD}$ (defined by $\mathrm{FEV}_{1}<60 \%$ pred) or severe $\mathrm{PH}$-idiopathic pulmonary fibrosis (defined by $\mathrm{FVC}<70 \%$ pred).

All patients received a minimum of 3 months of disease-targeted therapy at the discretion of the prescribing $\mathrm{PH}$ physician. Patients with lung disease were treated with inhaled bronchodilators and LTOT in accordance 


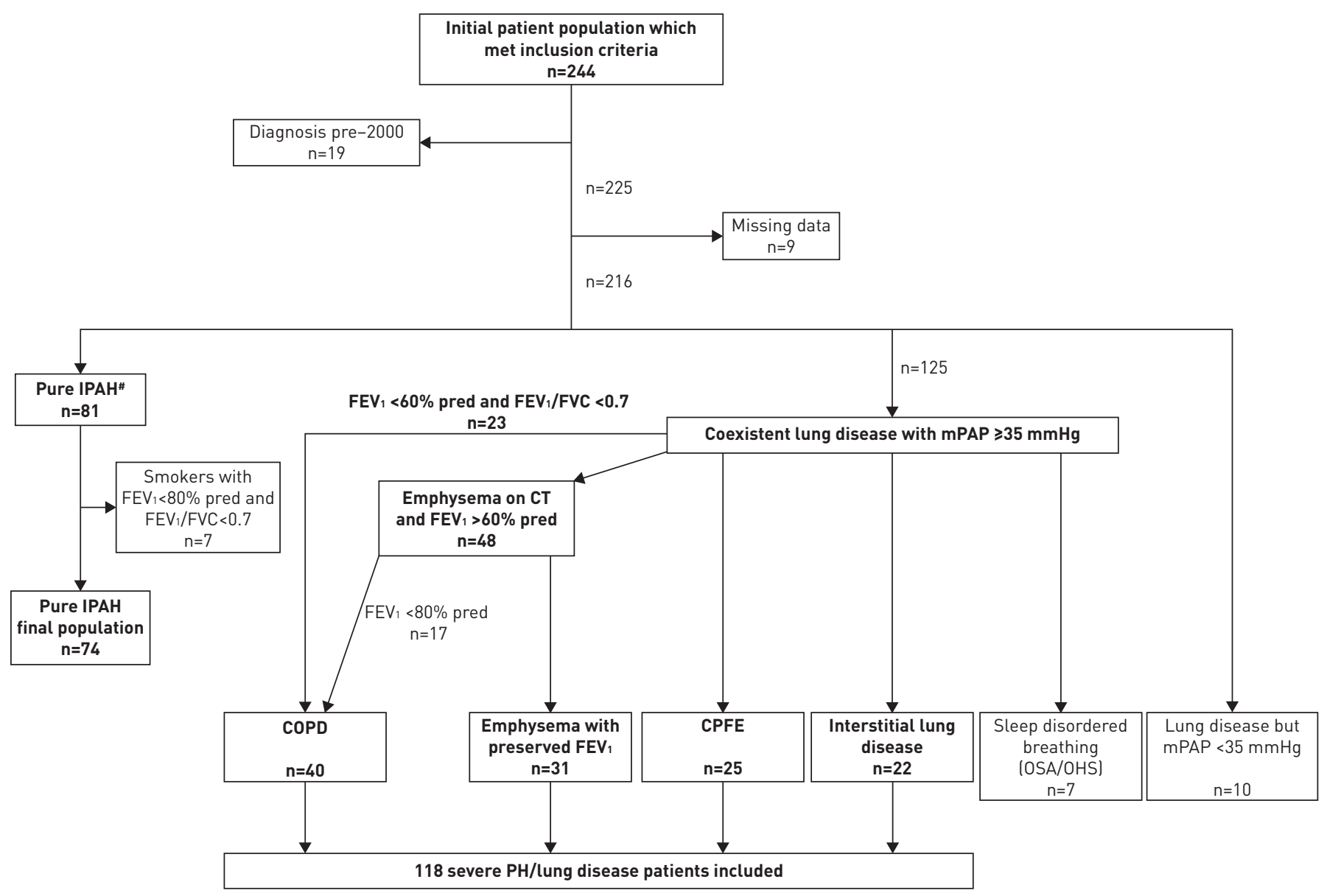

FIGURE 1 Population distribution. IPAH: idiopathic pulmonary arterial hypertension; mPAP: mean pulmonary arterial pressure; FEV1: forced expiratory volume in $1 \mathrm{~s}$; \% pred: \% predicted; FVC: forced vital capacity; COPD: chronic obstructive pulmonary disease; CPFE: combined pulmonary fibrosis and emphysema syndrome; OSA: obstructive sleep apnoea; OHS: obesity hypoventilation syndrome. ": "pure" IPAH group had neither parenchymal disease nor spirometric abnormalities.

with UK guidelines $[21,22]$ and compassionate use of PH-targeted therapy. NYHA functional class, 6MWD and NT-proBNP were measured at diagnosis and reassessed at a time point $>3$ months. Cardiac magnetic resonance imaging (MRI) variables were indexed for body surface area and adjusted for age.

\section{Statistical analysis}

Statistical analysis was performed using SPSS 21 (SPSS Inc., Chicago, IL, USA) and GraphPad Prism (version 5.00; GraphPad Software, La Jolla, CA, USA). Continuous variables were tested for normality using the D'Agostino-Pearson omnibus normality test. Normally distributed variables are shown as mean \pm SD and non-normally distributed variables as median (interquartile range (IQR)). Categorical variables are described by percentages (n), unless otherwise stated. Comparison of baseline characteristics between phenotypes was made using unpaired t-tests or Mann-Whitney U-tests, depending on data distribution. Comparison of several groups was performed using ANOVA or Kruskal-Wallis tests with post hoc analysis using Tukey's or Dunn's multiple comparison test. Comparison between baseline and follow-up 6MWD and NT-proBNP was made by paired t-test or Wilcoxon signed rank test. Comparison between categorical variables was made using Chi-squared.

Survival was from date of diagnostic RHC and the study end-point was either date of death, lung transplant or censoring. Patients were censored if they were lost to follow-up or alive at last day of the study (August 5, 2014). All-cause mortality was used for survival analysis. Kaplan-Meier survival curves were performed to estimate 1- and 3-year survival with comparison of groups using log-rank testing. Survival predictors were determined using Cox proportional hazards regression analysis. Variables with $\mathrm{p} \leqslant 0.2$ were considered for multivariate analysis. Indicator variable coding for missing data was used for multivariate analysis. At 3 months, 6MWD and NT-proBNP were dichotomised according to the median, and Kaplan-Meier survival curves compared using log-rank test. $\mathrm{p}<0.05$ was considered statistically significant throughout. 


\section{Results}

\section{Baseline characteristics}

118 patients had severe PH with coexistent lung disease and 74 patients had IPAH. Table 1 shows the characteristics of the two groups. IPAH patients were younger, more often female, had higher baseline NYHA functional class and 6MWD, and lower NT-proBNP despite worse haemodynamics. Phosphodiesterase-5 inhibitors were more commonly prescribed in those with lung disease. In those with COPD, FEV1 correlated with 6MWD ( $\mathrm{r}=0.458, \mathrm{p}=0.006)$.

There were 31 patients with emphysema/preserved FEV1, 25 patients with CPFE, 22 patients with ILD (nonspecific interstitial pneumonia $\mathrm{n}=7$, usual interstitial pneumonia $\mathrm{n}=8$, cryptogenic organising pneumonitis $n=1$ and indeterminate fibrosis $n=6$ ) and 40 COPD patients. Of these 40 patients, 28 had emphysema, four had respiratory bronchiolitis and three patients were shown to have bronchiectasis on imaging. Five patients had isolated spirometric abnormalities. Table 2 shows the characteristics of the lung phenotype groups. 88 patients met the criteria suggested by SEEGER et al. [10]. 30 patients had marked

\begin{tabular}{|c|c|c|c|}
\hline & IPAH & All lung disease & p-value \\
\hline Subjects & 74 & 118 & \\
\hline Age years & $49 \pm 18$ & $67 \pm 9$ & $<0.0001^{* * *}$ \\
\hline Female \% & 72 & 45 & $<0.0001^{* * *}$ \\
\hline Ever-smokers & $32(22)$ & 90 (105) & \\
\hline Smoking pack-years & $30 \pm 15$ & $42 \pm 24$ & $0.048^{*}$ \\
\hline \multicolumn{4}{|l|}{ Baseline haemodynamics } \\
\hline mPAP $\mathrm{mmHg}$ & $54(46-62)$ & $47(42-51)$ & $<0.0001^{* * *}$ \\
\hline $\mathrm{RAP} \mathrm{mmHg}$ & $8 \pm 6$ & $9 \pm 5^{\#}$ & 0.873 \\
\hline Cardiac index $\mathrm{L} \cdot \mathrm{min}^{-1} \cdot \mathrm{m}^{-2}$ & $2.0 \pm 0.5^{\pi}$ & $1.9 \pm 0.5^{+}$ & 0.159 \\
\hline PVR Wood units & $12.5(9.2-17.9)$ & $10.7(8.3-14.7)$ & $0.034^{*}$ \\
\hline PAWP $\mathrm{mmHg}$ & $7 \pm 4$ & $8 \pm 3$ & 0.077 \\
\hline $\mathrm{SvO}_{2} \%$ & $63(56-69)^{\S}$ & $61(53-67)$ & 0.315 \\
\hline Peripheral oxygen saturations & $96(94-98)$ & $94(91-97)^{f}$ & 0.011 \\
\hline Supplementary oxygen \% & $22.7(15)$ & $70.0(77)$ & \\
\hline Flow rate $\mathrm{L} \cdot \mathrm{min}^{-1}$ & $5(2-10)$ & $4(2-15)$ & \\
\hline \multicolumn{4}{|l|}{ Initial PH therapy } \\
\hline $\mathrm{CCB}$ & $9.5(7)$ & $2.5(3)$ & $0.005^{* *}$ \\
\hline PDE-5 inhibitor & $44.6(33)$ & $66.9(79)$ & \\
\hline ERA & 25.7 (19) & $22.9(27)$ & \\
\hline Prostanoid & $14.9(11)$ & $4.2(5)$ & \\
\hline Combination & $5.4(4)$ & $3.4(4)$ & \\
\hline \multicolumn{4}{|l|}{ Lung function } \\
\hline FEV $1 \%$ pred & $91(83-97)$ & $77(60-94)$ & $<0.0001^{* * *}$ \\
\hline FVC $\%$ pred & $101 \pm 13$ & $96 \pm 26$ & 0.085 \\
\hline $\mathrm{FEV}_{1} / \mathrm{FVC} \%$ & $76(70-79)$ & $63(55-71)$ & $<0.0001^{* * *}$ \\
\hline TLC \% & $93 \pm 10^{\# \#}$ & $92 \pm 17$ กิศ & 0.616 \\
\hline DLco \% pred & $62(39-76)^{++}$ & $24(19-33)^{\S \S}$ & $<0.0001^{* * *}$ \\
\hline $\mathrm{PaO}_{2} \mathrm{kPa}$ & $9.6 \pm 2^{f f}$ & $7.3 \pm 1.6^{\# \# \#}$ & $<0.0001^{* * *}$ \\
\hline $\mathrm{PaCO}_{2} \mathrm{kPa}$ & $4.1 \pm 0.7^{f f}$ & $4.0 \pm 0.7^{\# \# \#}$ & 0.834 \\
\hline \multicolumn{4}{|l|}{ NYHA functional class } \\
\hline $1 / I I$ & 23.9 (17) & $11.4(13)$ & $0.020^{*}$ \\
\hline III & $69.0(49)$ & $71.1(81)$ & \\
\hline IV & $7.0(5)$ & $16.9(20)$ & \\
\hline 6MWD m & 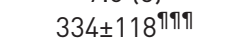 & $202 \pm 108^{\S \S}$ & $<0.0001^{* * *}$ \\
\hline NT-proBNP pg.mL ${ }^{-1}$ & $1128(508-2890)^{+++}$ & $2245(943-4225)^{\S \S \S}$ & $0.018^{*}$ \\
\hline
\end{tabular}

Data are presented as $n$, mean $\pm S D, \%(n)$ or median (interquartile range), unless otherwise stated. IPAH: idiopathic pulmonary arterial hypertension; mPAP: mean pulmonary arterial pressure; RAP: right atrial pressure; PVR: pulmonary vascular resistance; PAWP: pulmonary arterial wedge pressure; $\mathrm{SvO}_{2}$ : mixed venous oxygen saturation; $\mathrm{PH}$ : pulmonary hypertension; $\mathrm{CCB}$ : calcium-channel blocker; PDE: phosphodiesterase; ERA: endothelin receptor antagonists; FEV1: forced expiratory volume in $1 \mathrm{~s}$; $\%$ pred: \% predicted; FVC: forced vital capacity; TLC: total lung capacity; DLCO: diffusing capacity of the lung for carbon monoxide; $\mathrm{PaO}_{2}$ : arterial oxygen tension; $\mathrm{PaCO}_{2}$ : arterial carbon dioxide tension; NYHA: New York Heart Association; 6MWD: 6-min walking distance; NT-proBNP: N-terminal pro-brain natriuretic

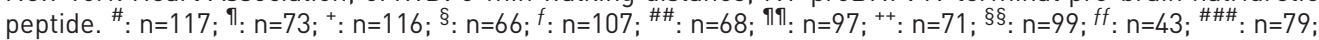
กाศी: $n=62 ;{ }^{+++}: n=46 ;$ §§§ $: n=90 .^{*}: p<0.05 ;{ }^{* *}: p<0.01 ;{ }^{* * *}: p<0.001$. 
TABLE 2 Population characteristics of lung disease phenotypes

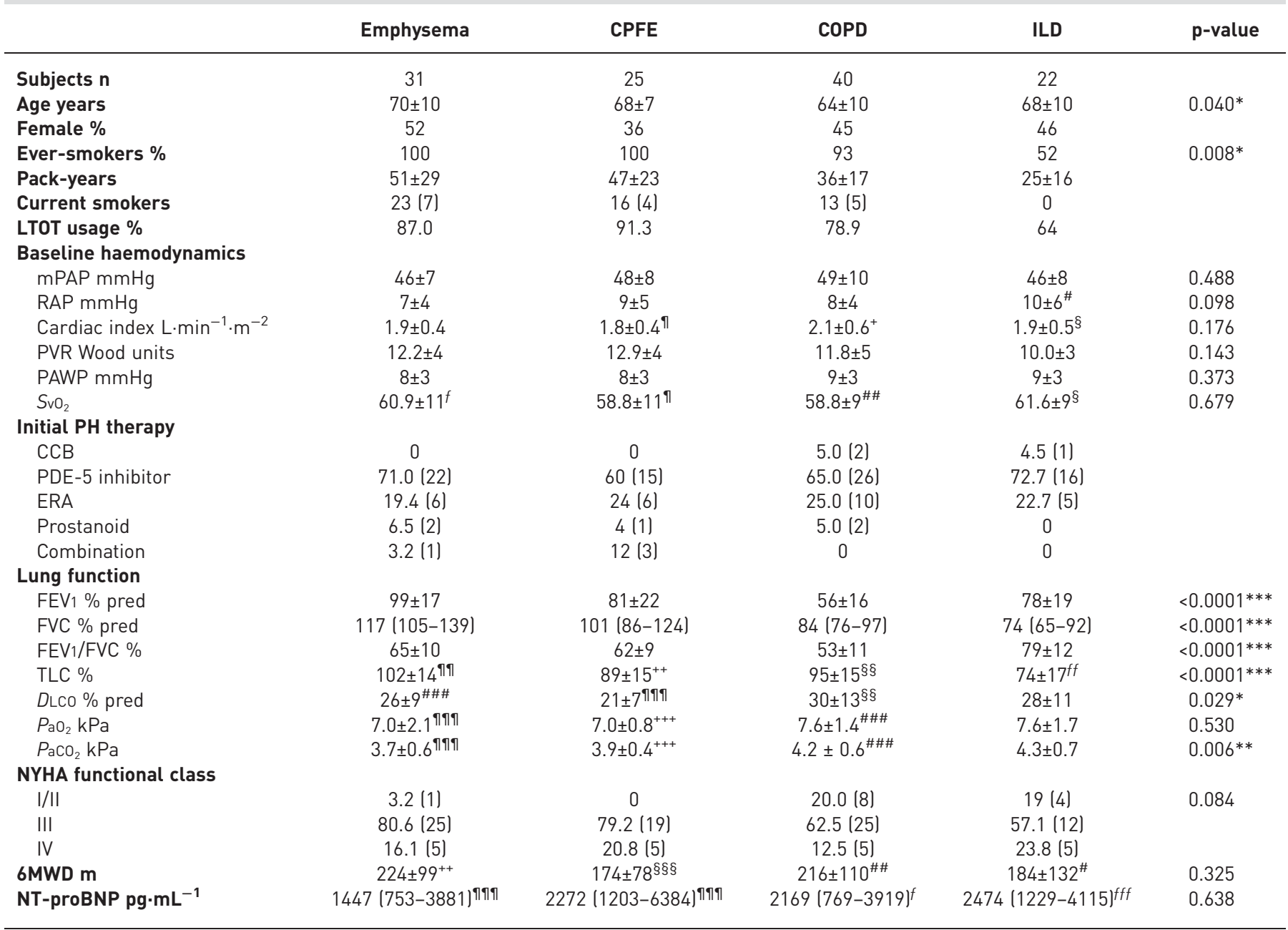

Data are presented as $\mathrm{n}$, mean $\pm \mathrm{SD}, \%$ (n) or median (interquartile range), unless otherwise stated. $\mathrm{p}$-values are Chi-squared, ANOVA or KruskalWallis, depending on data distribution. CPFE: combined pulmonary fibrosis and emphysema syndrome; COPD: chronic obstructive pulmonary disease; ILD: interstitial lung disease; LTOT: long-term oxygen therapy; mPAP: mean pulmonary arterial pressure; RAP: right atrial pressure; PVR: pulmonary vascular resistance; PAWP: pulmonary arterial wedge pressure; $\mathrm{SvO}_{2}$ : mixed venous oxygen saturation; $\mathrm{PH}$ : pulmonary hypertension; CCB: calcium-channel blocker; PDE: phosphodiesterase; ERA: endothelin receptor antagonists; FEV1: forced expiratory volume in $1 \mathrm{~s} ; \%$ pred: \% predicted; FVC: forced vital capacity; TLC: total lung capacity; DLCo: diffusing capacity of the lung for carbon monoxide; $P \mathrm{aO}_{2}$ : arterial oxygen tension; $\mathrm{PaCO}_{2}$ : arterial carbon dioxide tension; NYHA: New York Heart Association; 6MWD: 6-min walking distance; NT-proBNP: N-terminal

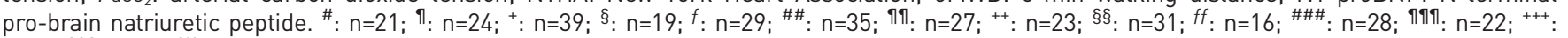
$n=15 ;{ }^{\S \S}: n=20 ;{ }^{f f f}: n=17 .{ }^{*}: p<0.05 ; * *: p<0.01 ;{ }^{* * *}: p<0.001$.

emphysema on CT, but preserved $\mathrm{FEV}_{1}$ ( $>80 \%$ pred) and were excluded, as this group was not considered by this classification. 32 patients met the criteria for severe $\mathrm{PH} / \mathrm{mild}$ lung disease and 56 patients were classified as having severe $\mathrm{PH} /$ severe lung disease (severe $\mathrm{PH}-\mathrm{CPFE} \mathrm{n}=22$, severe $\mathrm{PH}-\mathrm{COPD} \mathrm{n}=24$ and severe PH-ILD $\mathrm{n}=10$ ).

\section{Prognostic indicators and survival}

28 patients (IPAH $n=9$, COPD $n=3, \operatorname{CPFE} n=5$, ILD $n=2$ and emphysema $n=9$ ) were unable to perform $6 \mathrm{MWD}$ at diagnosis. 18 patients died prior to their first follow-up (IPAH $n=4$, emphysema $n=4$, CPFE $n=1$, ILD $n=6$, COPD $n=3$ ). Of these, nine were unable to walk at diagnosis. Median time to follow-up did not differ between IPAH and lung disease groups (111 (97-150) days versus 111 (96-148) days, p=0.888). In the IPAH group there were 25 deaths, and two patients underwent lung transplantation during the follow-up period, compared with 81 deaths in those with lung disease (CPFE $n=19$, ILD $n=15$, emphysema $\mathrm{n}=23$ and COPD $\mathrm{n}=24$ ). Survival was worse in those with lung disease. 1- and 3-year estimated survival rates in lung disease compared to IPAH were $76.3 \%$ versus $90.3 \%$ and $38.8 \%$ versus $72 \%$, respectively $(\mathrm{p}<0.0001)$. The presence of lung disease remained an independent predictor when the 
older age of this cohort in comparison to IPAH patients was considered using multivariate analysis $(\mathrm{p}=0.009)$. Survival between lung phenotypes after age adjustment was not significantly different, with the exception of ILD patients, where survival was worse. There was no significant difference in survival between those meeting the criteria suggested by SEEGER et al. [10] for those with severe PH/mild lung disease versus those with severe $\mathrm{PH} /$ severe lung disease, with the exception of severe $\mathrm{PH}-\mathrm{ILD}$ where survival was poorer. Kaplan-Meier survival curves are shown in online supplementary figures S1 and S2.

\section{Baseline predictors of survival}

When modelled with age, DLCO and PVR, right atrial pressure (RAP), cardiac index and sex were independent predictors of survival in the lung disease cohort. In IPAH, DLCO, male sex and 6MWD were found to be a predictors (table 3). The coding variable for missing 6MWD was also an independent predictor of survival in those with lung disease (hazard ratio (HR) 2.17, 95\% CI 1.199-3.929; p=0.010), suggesting that the inability to perform $6 \mathrm{MWD}$ is a prognostic variable.

Univariate analysis of the lung phenotypes is shown in online supplementary table S1. In a model with age, mPAP and cardiac index, RAP was an independent predictor of survival in the emphysema cohort (HR 1.423, 95\% CI 1.063-1.742; $\mathrm{p}=0.001$ ). Comparative analysis of survivors and nonsurvivors at 3 years is presented in online supplementary table S2.

\section{Cardiac MRI}

Cardiac MRI data were available for 55 patients with lung disease (COPD n=14, ILD n=8, CPFE $n=15$, emphysema $\mathrm{n}=18$ ) and 35 IPAH patients. There were no significant differences between right and left ventricular function between the two groups (online supplementary table S3). Lung disease patients were older (66 versus 48 years, $\mathrm{p}<0.0001$ ) with a more significant smoking history $(51$ out of 55 previous smokers versus 11 out of 35$)$.

In those with lung disease, right ventricular (RV) function was reduced (RV ejection fraction (RVEF) 33 $\pm 13 \%$ ) with increased RV volumes and RV mass index (RVMI) $\left(92 \pm 30 \mathrm{~mL} \cdot \mathrm{m}^{-2}\right.$ and 50 (39-59) $\mathrm{g} \cdot \mathrm{m}^{-2}$, respectively). NT-proBNP moderately correlated with RVEF $(\mathrm{r}=-0.653, \mathrm{p}<0.0001)$ and weakly with RV end-diastolic volume (RVEDV) $(\mathrm{r}=0.422, \mathrm{p}=0.003)$. There were no significant correlations between lung function and RV or left ventricular function.

Univariate Cox regression of cardiac MRI indices with adjustment for age is shown in table 4. RVMI and stroke volume remained independent predictors of survival on multivariate analysis in a model with mPAP, RAP, age and sex (HR 1.026, 95\% CI 1.002-1.051; p=0.033 and HR 0.908, 95\% CI 0.857-0.962; $\mathrm{p}=0.001$, respectively). Excluding those with ILD, who were more commonly nonsmokers with less cardiovascular risk, left ventricular ejection fraction (LVEF) (HR 0.965, 95\% CI 0.933-0.984; p=0.037), stroke volume (HR 0.908, 95\% CI 0.851-0.969; $\mathrm{p}=0.003$ ) and RVMI (HR 1.028, 95\% CI 1.003-1.054; $\mathrm{p}=0.028$ ) were independent predictors of survival (online supplementary table S4).

\section{NT-proBNP and 6MWD at 3 months}

Kaplan-Meier survival curves were derived according to the median 6MWD and NT-proBNP at follow-up for patients with lung disease (online supplementary figure S3). Patients unable to perform a 6-min walk test (6MWT) despite treatment had significantly worse survival (1-year survival $97.2 \%$ versus $87.1 \%$ versus $58.3 \%$ and 3 -year survival $56.7 \%$ versus $48.2 \%$ versus $20.8 \%$ in those with $6 \mathrm{MWD}>231 \mathrm{~m}, \leqslant 231 \mathrm{~m}$ and unable to perform $6 \mathrm{MWT}$, respectively; $\mathrm{p}=0.001$ and $\mathrm{p}=0.003$ ). A level of NT-proBNP $<1449 \mathrm{pg} \cdot \mathrm{mL}^{-1}$ in the lung disease group was associated with improved survival (1-year survival $95.0 \%$ versus $78.9 \%$ and 3 -year survival $65.8 \%$ versus $23.6 \%$; $\mathrm{p}<0.0001$ ).

\section{Treatment response}

There were significant improvments in 6MWD and NT-proBNP in the IPAH group. No improvements were observed in 6MWD or NYHA functional class for lung disease patients; however NT-proBNP decreased (2200 (850-4122) $\mathrm{pg} \cdot \mathrm{mL}^{-1}$ to 1596 (614-3180) $\left.\mathrm{pg} \cdot \mathrm{mL}^{-1} ; \mathrm{p}=0.015\right)$. Baseline and follow-up variables for each group are shown in table 5. Figure 2 shows the change in NT-proBNP and 6MWD with treatment for each cohort. In a model with age, sex, baseline RAP, cardiac index and mPAP, change in NT-proBNP but not 6MWD independently predicted survival in the lung disease group only (HR 1.508, 95\% CI 1.062-2.142; $\mathrm{p}=0.022$ ).

Exercise oxygen saturation data were available for 47 patients with lung disease. No increase in desaturation upon exercise following $\mathrm{PH}$ therapy was observed $(-8(-30--6) \%$ to $-9(-15-6) \%$, $\mathrm{p}=0.834)$. 
TABLE 3 Cox regression survival analysis to identify predictors of survival in patients with severe pulmonary hypertension and lung disease in comparison to those with idiopathic pulmonary arterial hypertension (IPAH)

\begin{tabular}{|c|c|c|c|c|c|c|c|c|}
\hline & \multicolumn{4}{|c|}{ Univariate model } & \multicolumn{4}{|c|}{ Multivariate model } \\
\hline & IPAH & $\mathrm{p}$-value & Lung disease & $\mathrm{p}$-value & IPAH & $\mathrm{p}$-value & Lung disease & p-value \\
\hline Age & $1.047(1.002-1.074)$ & 0.001 & $1.042(1.016-1.069)$ & 0.001 & $1.012(0.981-1.043)$ & 0.460 & $1.020(0.992-1.049)$ & 0.161 \\
\hline Sex & $0.911(0.383-2.165)$ & 0.833 & $0.682(0.392-0.986)$ & 0.043 & $0.339(0.120-0.952)$ & 0.040 & $0.564(0.340-0.934)$ & 0.026 \\
\hline 6MWD & $0.994(0.990-0.998)$ & 0.003 & $0.997(0.994-0.999)$ & 0.007 & $0.994(0.998-0.999)$ & 0.020 & & \\
\hline NT-proBNP & $1.066(0.756-1.503)$ & 0.717 & $1.349(1.179-1.882)$ & 0.001 & & & & \\
\hline \multicolumn{9}{|c|}{ Haemodynamic variables } \\
\hline mPAP & $1.005(0.976-1.034)$ & 0.744 & $0.830(0.961-1.007)$ & 0.166 & & & & \\
\hline RAP & $1.006(0.942-1.075)$ & 0.855 & $1.091(1.047-1.138)$ & $<0.0001$ & & & $1.084(1.027-1.145)$ & 0.004 \\
\hline PVR & 1.009 (0.950-1.072) & 0.767 & $1.030(0.985-1.078)$ & 0.194 & $1.036(0.964-1.113)$ & 0.335 & $0.971(0.905-1.041)$ & 0.404 \\
\hline Cardiac index & $0.912(0.436-1.905)$ & 0.805 & $0.294(0.171-0.507)$ & $<0.0001$ & & & $0.349(0.169-0.724)$ & 0.005 \\
\hline PAWP & $0.964(0.872-1.066)$ & 0.477 & $0.997(0.929-1.069)$ & 0.926 & & & & \\
\hline $\mathrm{SvO}_{2}$ & $0.989(0.948-1.032)$ & 0.605 & $0.974(0.954-0.996)$ & 0.023 & & & & \\
\hline \multicolumn{9}{|l|}{ Lung function } \\
\hline$D\llcorner C O$ & $0.954(0.934-0.975)$ & $<0.0001$ & $0.974(0.953-0.996)$ & 0.021 & $0.966(0.941-0.992)$ & 0.011 & $0.978(0.954-1.003)$ & 0.084 \\
\hline $\mathrm{PaO}_{2}$ & 0.808 (0.597-1.094) & 0.168 & $0.808(0.643-1.014)$ & 0.065 & & & & \\
\hline $\mathrm{FEV}_{1}$ & $1.003(0.968-1.038)$ & 0.879 & $1.004(0.995-1.012)$ & 0.368 & & & & \\
\hline $\mathrm{FEV}_{1} / \mathrm{FVC}$ & $0.923(0.873-0.997)$ & 0.006 & $1.022(1.003-1.041)$ & 0.022 & & & & \\
\hline
\end{tabular}

Data are presented as hazard ratio $(95 \% \mathrm{CI})$, unless otherwise stated. Bold type represents statistically significant predictors of survival. 6MWD: 6-min walking distance; NT-proBNP: $\mathrm{N}$-terminal pro-brain natriuretic peptide; mPAP: mean pulmonary arterial pressure; RAP: right atrial pressure; PVR: pulmonary vascular resistance; PAWP: pulmonary arterial wedge pressure; $\mathrm{SvO}_{2}$ : mixed venous oxygen saturation; DLCO: diffusing capacity of the lung for carbon monoxide; $\mathrm{PaO}_{2}$ : arterial oxygen tension; FEV 1 : forced expiratory volume in $1 \mathrm{~s}$; FVC: forced vital capacity. 
TABLE 4 Cox proportional hazard regression analysis of cardiac magnetic resonance imaging indices of right and left ventricular function in patients with severe pulmonary hypertension and lung disease

\begin{tabular}{|c|c|c|c|c|}
\hline & Univariate model & p-value & Multivariate model $^{\#}$ & p-value \\
\hline RVEF \% & $0.925(0.890-0.962)$ & $<0.001$ & & \\
\hline LVEF \% & $0.969(0.944-0.994)$ & 0.017 & & \\
\hline Stroke volume $\mathrm{mL} \cdot \mathrm{m}^{-2}$ & $0.920(0.873-0.970)$ & 0.002 & $0.908(0.857-0.962)$ & 0.001 \\
\hline RVESV $\mathrm{mL} \cdot \mathrm{m}^{-2}$ & $1.022(1.009-1.036)$ & 0.001 & & \\
\hline RVEDV $\mathrm{mL} \cdot \mathrm{m}^{-2}$ & $1.016(1.004-1.029)$ & 0.009 & & \\
\hline LVEDV $\mathrm{mL} \cdot \mathrm{m}^{-2}$ & $0.992(0.970-1.014)$ & 0.484 & & \\
\hline RVMI $g \cdot m^{-2}$ & $1.032(1.011-1.054)$ & 0.003 & $1.026(1.002-1.051)$ & 0.033 \\
\hline LVMI $\mathrm{g} \cdot \mathrm{m}^{-2}$ & $1.004(0.979-1.029)$ & 0.760 & & \\
\hline
\end{tabular}

Data are presented as hazard ratio $(95 \% \mathrm{CI})$, unless otherwise stated. RVEF: right ventricular ejection fraction; LVEF: left ventricular ejection fraction; RVESV: right ventricular end-systolic volume; RVEDV: right ventricular end-diastolic volume; LVEDV: left ventricular end-diastolic volume; RVMI: right ventricular mass index; LVMI: left ventricular mass index. ${ }^{\#}$ : with age, sex, right atrial pressure and mean pulmonary arterial pressure.

\section{Discussion}

We report the characteristics, survival and response to pulmonary vasodilator therapy in four distinct lung disease phenotypes with severe $\mathrm{PH}$ and compare this with a group of patients with IPAH. During the 14-year study period, more patients with coexistent lung disease than pure IPAH were seen. This could possibly be explained by the large proportion of smokers (68\%) and older age of the study population (mean age 60 years). The demographics of incident IPAH cases has shown a trend towards increasing age at diagnosis, and increasing presence of comorbid diseases in PH registries [23]. In the REVEAL (Registry to Evaluate Early and Long-term PAH Disease Management) study up to $17 \%$ of PAH diagnoses had coexistent COPD [24]. This highlights the importance of assessing the impact of coexistent lung disease on $\mathrm{PH}$ therapy in efforts to develop management strategies for "real-life" patients, many of which are excluded in drug trials. Severe $\mathrm{PH}$ in lung disease patients described by our study demonstrated severe hypoxaemia, grossly impaired DLCO, relatively mild airflow obstruction and more severe functional impairment measured by NYHA functional class and 6MWD than IPAH patients, despite similar haemodynamics. Similar characteristics have previously been reported in patients with COPD and severe $\mathrm{PH}[2,19]$. A recent case series of three male smokers described a severe $\mathrm{PH}$ and emphysema phenotype with preserved lung volumes and impaired DLCO [25]. NT-proBNP was higher in the lung disease group than IPAH despite similar haemodynamics. Furthermore, RVMI was higher in those with IPAH than lung disease patients. This could suggest a greater degree of right ventricular dysfunction and impaired adaptation to afterload in lung disease patients. There was no significant difference in renal function to account for the higher NT-proBNP (Modification of Diet in Renal Disease estimated glomerular filtration rate $63(51-82) \mathrm{mL} \cdot \mathrm{min}^{-1} \cdot 1.73 \mathrm{~m}^{-2}$ versus $\left.71(53-82) \mathrm{mL} \cdot \mathrm{min}^{-1} \cdot 1.73 \mathrm{~m}^{-2}, \mathrm{p}=0.340\right)$. Lung disease patients were significantly older (67 versus 49 years) and NT-proBNP has been shown to increase with age, by $36 \%$ in men and $15 \%$ in females per 8.4 years in one study [26]. PVR was higher (and therefore so was RV afterload) in the IPAH patients who underwent MRI, and therefore we would expect a greater degree of RV adaptation. Additionally, RVMI has been shown to fall with age: a 5\% reduction per decade of age has been shown [27]. Differences in the demographics of the populations may therefore account for the apparent difference in NT-proBNP and RVMI. Our study describes the largest treated population of patients with severe $\mathrm{PH}$ in lung disease and further explores the impact of lung disease phenotype on outcome. Suggested mechanisms leading to the development of $\mathrm{PH}$ include vascular ablation, excessive hypoxic pulmonary vasoconstriction, pulmonary artery remodelling and endothelial dysfunction from inflammation and exposure to cigarette smoke [28]. One hypothesis may be that the emphysema phenotype described in this study demonstrated a poorer response to therapy because the pathophysiology may relate more to vascular loss than potentially treatment-responsive vascular dysfunction.

Survival in those with lung disease was worse, in comparison to IPAH, despite age adjustment. ILD patients displayed poorer survival in comparison to other lung phenotypes, with six out of 22 patients dying prior to the first follow-up assessment. We have identified sex, the inability to perform a $6 \mathrm{MWT}$, cardiac index and RAP as independent predictors of survival in severe $\mathrm{PH}$ with lung disease. In the subset that underwent cardiac MRI, stroke volume and RVMI were independent predictors of survival.

Our results show that despite similar baseline haemodynamics, patients with severe $\mathrm{PH}$ and lung disease in comparison to IPAH do not respond to treatment with $\mathrm{PH}$ therapy when outcome measures such as 


\begin{tabular}{|c|c|c|c|c|}
\hline & Subjects & Baseline & Follow-up & p-value \\
\hline \multicolumn{5}{|l|}{ IPAH } \\
\hline 6MWD m & 58 & $337 \pm 114$ & $376 \pm 97$ & $<0.0001^{* * *}$ \\
\hline NT-proBNP pg.mL ${ }^{-1}$ & 42 & 1085 (449-2545) & 788 (289-1655) & $0.001^{* *}$ \\
\hline NYHA functional class I+II/III/IV & & $17 / 41 / 4$ & $30 / 29 / 3$ & 0.055 \\
\hline \multicolumn{5}{|l|}{ Lung disease (all) } \\
\hline 6MWD m & 75 & $226 \pm 101$ & $242 \pm 103$ & 0.087 \\
\hline NT-proBNP pg.mL ${ }^{-1}$ & 78 & $2200(850-4122)$ & $1596(614-3180)$ & $0.015^{*}$ \\
\hline NYHA functional class I+II/III/IV & & $11 / 73 / 12$ & $16 / 72 / 8$ & 0.421 \\
\hline \multicolumn{5}{|l|}{ COPD } \\
\hline 6MWD m & 30 & $222 \pm 113$ & $242 \pm 108$ & 0.113 \\
\hline $\mathrm{NT}-$ proBNP $\mathrm{pg} \cdot \mathrm{mL}^{-1}$ & 26 & $2335(562-4066)$ & $1822(411-3734)$ & 0.094 \\
\hline NYHA functional class I+II/III/IV & & $6 / 21 / 3$ & $9 / 19 / 2$ & 0.638 \\
\hline \multicolumn{5}{|l|}{ CPFE } \\
\hline 6MWD m & 16 & $191 \pm 70$ & $230 \pm 94$ & 0.103 \\
\hline NT-proBNP pg.mL ${ }^{-1}$ & 21 & $2258(1153-5992)$ & $2471(461-3325)^{\#}$ & $0.015^{*}$ \\
\hline NYHA functional class I+II/III/IV & & $0 / 19 / 4$ & $1 / 20 / 2$ & 0.429 \\
\hline \multicolumn{5}{|l|}{ Emphysema } \\
\hline $6 \mathrm{MWD} \mathrm{m}$ & 19 & $237 \pm 102$ & $224 \pm 88$ & 0.575 \\
\hline NT-proBNP pg.mL ${ }^{-1}$ & 19 & $1378(440-3881)$ & $1449(663-3082)$ & 0.365 \\
\hline NYHA functional class I+II/III/IV & & $1 / 23 / 3$ & $1 / 24 / 2$ & 0.895 \\
\hline \multicolumn{5}{|l|}{ ILD } \\
\hline 6MWD m & 10 & $275 \pm 92$ & $295 \pm 123$ & 0.324 \\
\hline NT-proBNP pg.mL ${ }^{-1}$ & 12 & $2466(1028-3991)$ & $1068(710-2837)$ & $0.021^{*}$ \\
\hline NYHA functional class I+II/III/IV & & $4 / 10 / 2$ & $5 / 9 / 2$ & 0.921 \\
\hline Severe $\mathrm{PH} /$ mild lung disease & 32 & & & \\
\hline 6MWD m & 22 & $255 \pm 109$ & $259 \pm 118$ & 0.788 \\
\hline NT-proBNP pg.mL ${ }^{-1}$ & 20 & $1852(645-5594)$ & 2073(599-3308) & 0.110 \\
\hline NYHA functional class I+II/III/IV & & $6 / 19 / 4$ & $6 / 19 / 4$ & 0.943 \\
\hline Severe $\mathrm{PH} /$ severe lung disease & 56 & & & \\
\hline 6MWD m & 35 & $185 \pm 85$ & $216 \pm 100$ & $0.021^{*}$ \\
\hline NT-proBNP pg.mL ${ }^{-1}$ & 41 & $2457(1229-5992)$ & $1831(580-3943)$ & $0.005^{* *}$ \\
\hline NYHA functional class I+II/III/IV & & $2 / 36 / 8$ & $7 / 36 / 3$ & 0.08 \\
\hline
\end{tabular}

Data are presented as $n$, mean \pm SD or median (interquartile range), unless otherwise stated. IPAH: idiopathic pulmonary arterial hypertension; 6MWD: 6-min walking distance; NT-proBNP: N-terminal pro-brain natriuretic peptide; NYHA: New York Heart Association; COPD: chronic obstructive pulmonary disease; CPFE: combined pulmonary fibrosis and emphysema syndrome; ILD: interstitial lung disease. \#: in CPFE, while median NT-proBNP increased, a reduction in NT-proBNP was seen in 14 out of 21 cases, median change in NT-proBNP $-596 \mathrm{pg} \cdot \mathrm{mL}^{-1}$ and mean NT-proBNP decreased from $4543 \pm 7426$ to 3002 $\pm 3850 \mathrm{pg} \cdot \mathrm{mL}^{-1}$. The increase in median values probably reflects nonparametric distribution. *: $p<0.05$; $* *: p<0.01 ;{ }^{* * *}: p<0.001$.

6MWD or NYHA functional class are considered; however, improvement in NT-proBNP was demonstrated. The response to therapy differs between lung phenotype groups. Those with emphysema and preserved FEV1 showed no improvement in any outcome measure, and perhaps displayed evidence of deterioration in the 3-month observation period with a nonsignificant fall in 6MWD. ILD patients had the worst survival, although a reduction in NT-proBNP was demonstrated, albeit in a small population. Those with CPFE showed significant decreases in NT-proBNP. Survival analysis suggested that NT-proBNP may be a better outcome measure than 6MWD in those with lung disease where exercise capacity will be ventilatory-limited in addition to cardiovascular limitation. The negative correlation observed between FEV1 and 6MWD in those with COPD could support this ventilatory limitation [29]. Surprisingly, using the classification suggested by SEEGER et al. [10], no difference in survival was suggested between those with severe $\mathrm{PH} / \mathrm{mild}$ lung disease and severe $\mathrm{PH} /$ severe lung disease groups, with the exception of severe PH-ILD, which similarly to the overall ILD cohort showed poor survival. In addition, those with severe-PH/severe lung disease demonstrated improvements in both 6MWD and NT-proBNP with therapy whereas those who were classified as having co-existent mild lung disease did not.

NT-proBNP correlated with RVEF and RVEDV, so we can speculate that disease-targeted therapy may lead to improved outcome in those with improved RV function. Reduced LVEF as a prognostic variable in 

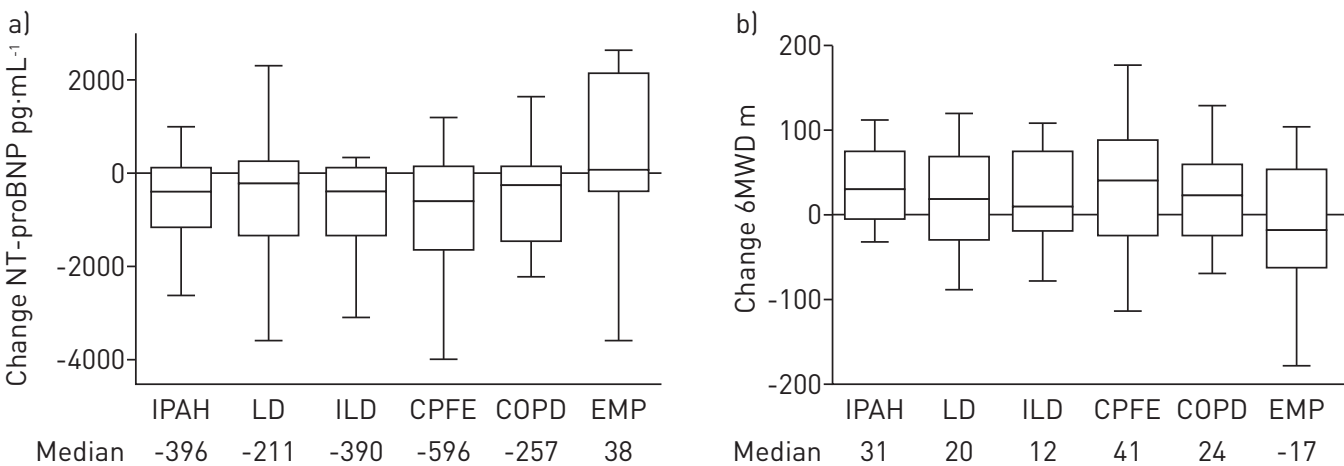

FIGURE 2 al Change in N-terminal pro-brain natriuretic peptide (NT-proBNP) following 3 months of pulmonary hypertension (PH) therapy by group. No significant difference was observed between groups; b) change in 6-min walking distance (6MWD) following 3 months of $\mathrm{PH}$ therapy. There was no significant difference between lung disease (LD) and idiopathic pulmonary arterial hypertension (IPAH) or across lung phenotypes seen. Data are presented as median and Tukey hinges. ILD: interstitial lung disease; CPFE: combined pulmonary fibrosis and emphysema syndrome; COPD: chronic obstructive pulmonary disease; EMP: emphysema.

severe $\mathrm{PH}$ with lung disease occurred without clinical left ventricular dysfunction and normal PAWP. Evidence of subclinical left ventricular dysfunction on echocardiogram has been reported in COPD [30] alongside increased risk of cardiovascular abnormalities including increased arterial stiffness [31-33], ischaemic heart disease and heart failure. Left ventricular dysfunction has been shown to relate to fat-free mass and interleukin-6 linking to the catabolic-inflammatory COPD phenotype and increased arterial stiffness [30]. 51 out of 55 patients who underwent cardiac MRI were smokers with an average 40 pack-year history. Smoking has been shown to have acute effects on aortic pulse wave velocity (a measure of vascular stiffness) [34] and left ventricular function [35].

The ASPIRE registry reported similar 1-year but worse 3-year survival rates of $70 \%$ and $33 \%$, respectively, compared to $79 \%$ and $47 \%$, respectively, in our cohort (ILD excluded). 43 out of 59 patients received $\mathrm{PH}$ therapy and were of similar age to our cohort, but had a greater degree of pulmonary function impairment (FEV1 65\% pred) and included patients with elevated PAWP. In addition they defined severe PH as mPAP $\geqslant 40 \mathrm{mmHg}$. ASPIRE reported mixed venous oxygen saturation, age, NYHA functional class IV and DLCO as independent predictors of survival, but included patients with mild and moderate $\mathrm{PH}$ in survival analysis [19]. Direct comparison with our cohort is therefore not possible. CotTin et al. [36] reported outcomes of 40 patients with $\mathrm{PH}$ in CPFE syndrome, of whom $24(60 \%)$ received $\mathrm{PH}$ therapy. They reported no improvement in $6 \mathrm{MWD}$, echocardiogram-derived pulmonary artery systolic pressure or NYHA functional class. Survival was significantly worse than reported here, with 1-year survival of only $60 \%$. Similar to ASPIRE, they included patients with mild-to-moderate PH (mPAP 24-56 mmHg), but found that higher PVR, lower cardiac index and DLCO predicted worse survival.

There is no evidence in the literature to support the use of pulmonary vasodilators in severe $\mathrm{PH}$ with lung disease. Previous studies have been of small sample size, did not always include RHC-derived mPAP and included patients with mild or even no PH $[16,18,37]$. Bosentan treatment for 12 weeks in 30 patients with severe COPD (six of whom had $\mathrm{PH}$ on echocardiography) showed no functional benefit [18]. Similarly, a 12-week trial of sildenafil in 15 severe COPD patients (nine with $\mathrm{PH}$ ) found no improvement in exercise capacity [16]. BLANCO et al. [38] demonstrated a fall in mPAP following acute administration of sildenafil in 20 COPD patients with mPAP $>20 \mathrm{mmHg}$ (or $>30 \mathrm{mmHg}$ on exercise) at RHC, but also demonstrated a fall in arterial oxygen tension $\left(\mathrm{PaO}_{2}\right)$ due to increased ventilation-perfusion mismatch. We did not demonstrate a deterioration in oxygen desaturation on 6MWT, although this should be interpreted with caution given the retrospective analysis of these data. The lack of demonstrated improvement in 6MWD in those with lung disease may suggest lack of efficacy of treatment. We did not demonstrate a survival benefit in those who improved 6MWD on treatment. This should be interpreted with caution as it may be that these patients were more ventilatory-limited so an alternative end-point should be used to determine efficacy. It is also possible that treatment led to a stabilisation of the clinical condition, as $6 \mathrm{MWD}$ did not fall at 3 months. A prospective trial with an untreated control arm could investigate this possibility further.

Improvement in NT-proBNP, a marker of RV dysfunction, is encouraging. Previous studies have not used this biomarker as outcome measure in PH associated with lung disease. In IPAH, NT-proBNP has been shown to correlate with RV function [39] and changes in serial NT-proBNP with treatment have been shown to predict survival [40]. In COPD, NT-proBNP has been shown to predict outcome following acute 
exacerbations of airways disease [41-43], identify those with concurrent left ventricular dysfunction [42, 44] and function as a screening tool for PH in COPD [45]. Our study demonstrates that NT-proBNP reflects RV dysfunction in severe $\mathrm{PH}$ lung disease patients, predicts survival on univariate analysis and, in addition, change in NT-proBNP predicted survival. This may reflect improvement in RV function, and be a useful marker of therapy response in future studies.

Our study has several limitations. This was a single-centre retrospective observational study which allowed for variation in therapy used for each cohort, and the numbers of patients in each lung disease phenotype were small. In addition, there was no control arm with severe $\mathrm{PH}$ and lung disease that did not receive therapy to contrast outcomes. Additionally, the CT evidence of lung disease was based on the multidisciplinary report. It was not possible to score the severity of emphysema on CT.

\section{Conclusion}

In comparison to IPAH patients, patients with severe $\mathrm{PH}$ associated with lung disease had poorer survival, which was driven by the ILD cohort and not abolished by adjusting for age. PH therapy did not lead to improvements in NYHA functional class or 6MWD; however, a reduction in NT-proBNP was seen. Survival and response to therapy may vary according to lung phenotype. Further studies with an untreated control group may establish if $\mathrm{PH}$ therapy has a role in delaying the progression of the pulmonary hypertension and improving survival.

\section{References}

1 Oswald-Mammosser M, Weitzenblum E, Quoix E, et al. Prognostic factors in COPD patients receiving long-term oxygen therapy. Importance of pulmonary artery pressure. Chest 1995; 107: 1193-1198.

2 Chaouat A, Bugnet AS, Kadaoui N, et al. Severe pulmonary hypertension and chronic obstructive pulmonary disease. Am J Respir Crit Care Med 2005; 172: 189-194.

3 Thabut G, Dauriat G, Stern JB, et al. Pulmonary hemodynamics in advanced COPD candidates for lung volume reduction surgery or lung transplantation. Chest 2005; 127: 1531-1536.

4 Scharf SM, Iqbal M, Keller C, et al. Hemodynamic characterization of patients with severe emphysema. Am J Respir Crit Care Med 2002; 166: 314-322.

5 Mejía M, Carrillo G, Rojas-Serrano J, et al. Idiopathic pulmonary fibrosis and emphysema: decreased survival associated with severe pulmonary arterial hypertension. Chest 2009; 136: 10-15.

6 Cottin V, Nunes H, Brillet PY, et al. Combined pulmonary fibrosis and emphysema: a distinct underrecognised entity. Eur Respir J 2005; 26: 586-593.

7 Weitzenblum E, Hirth C, Ducolone A, et al. Prognostic value of pulmonary artery pressure in chronic obstructive pulmonary disease. Thorax 1981; 36: 752-758.

8 Weitzenblum E, Schrijen F, Mohan-Kumar T, et al. Variability of the pulmonary vascular response to acute hypoxia in chronic bronchitis. Chest 1988; 94 : 772-778.

9 Eddahibi S, Chaouat A, Morrell N, et al. Polymorphism of the serotonin transporter gene and pulmonary hypertension in chronic obstructive pulmonary disease. Circulation 2003; 108: 1839-1844.

10 Seeger W, Adir Y, Barberà JA, et al. Pulmonary hypertension in chronic lung diseases. J Am Coll Cardiol 2013; 62: Suppl. 25, D109-D116.

11 Nocturnal Oxygen Therapy Trial Group. Continuous or nocturnal oxygen therapy in hypoxemic chronic obstructive lung disease: a clinical trial. Ann Intern Med 1980; 93: 391-398.

12 Weitzenblum E, Sautegeau A, Ehrhart M, et al. Long-term oxygen therapy can reverse the progression of pulmonary hypertension in patients with chronic obstructive pulmonary disease. Am Rev Respir Dis 1985; 131: 493-498.

13 Zieliński J, Tobiasz M, Hawryłkiewicz I, et al. Effects of long-term oxygen therapy on pulmonary hemodynamics in COPD patients: a 6-year prospective study. Chest 1998; 113: 65-70.

14 Timms RM, Khaja FU, Williams GW. Hemodynamic response to oxygen therapy in chronic obstructive pulmonary disease. Ann Intern Med 1985; 102: 29-36.

15 Holverda S, Rietema H, Westerhof N, et al. Stroke volume increase to exercise in chronic obstructive pulmonary disease is limited by increased pulmonary artery pressure. Heart 2009; 95: 137-141.

16 Rietema H, Holverda S, Bogaard HJ, et al. Sildenafil treatment in COPD does not affect stroke volume or exercise capacity. Eur Respir J 2008; 31: 759-764.

17 Dernaika TA, Beavin M, Kinasewitz GT. Iloprost improves gas exchange and exercise tolerance in patients with pulmonary hypertension and chronic obstructive pulmonary disease. Respiration 2010; 79: 377-382.

18 Stolz D, Rasch H, Linka A, et al. A randomised, controlled trial of bosentan in severe COPD. Eur Respir J 2008; 32: 619-628.

19 Hurdman J, Condliffe R, Elliot CA, et al. Pulmonary hypertension in COPD: results from the ASPIRE registry. Eur Respir J 2013; 41: 1292-1301.

20 Jankowich MD, Rounds SI. Combined pulmonary fibrosis and emphysema syndrome: a review. Chest 2012; 141: 222-231.

21 National Institute for Clinical Excellence. Management of Chronic Obstructive Pulmonary Disease in Adults in Primary and Secondary Care, CG101, 2010. Date last accessed: October 2013. Date last updated: July 2014.

22 Celli BR, MacNee W. Standards for the diagnosis and treatment of patients with COPD: a summary of the ATS/ ERS position paper. Eur Respir J 2004; 23: 932-946.

23 Ling Y, Johnson MK, Kiely DG, et al. Changing demographics, epidemiology, and survival of incident pulmonary arterial hypertension: results from the pulmonary hypertension registry of the United Kingdom and Ireland. Am J Respir Crit Care Med 2012; 186: 790-796. 
24 Poms AD, Turner M, Farber HW, et al. Comorbid conditions and outcomes in patients with pulmonary arterial hypertension: a REVEAL registry analysis. Chest 2013; 144: 169-176.

25 Adir Y, Shachner R, Amir O, et al. Severe pulmonary hypertension associated with emphysema: a new phenotype? Chest 2012; 142: 1654-1658.

26 Fradley MG, Larson MG, Cheng S, et al. Reference limits for N-terminal-pro-B-type natriuretic peptide in healthy individuals (from the Framingham Heart Study). Am J Cardiol 2011; 108: 1341-1345.

27 Kawut SM, Lima JA, Barr RG, et al. Sex and race differences in right ventricular structure and function: the Multi-ethnic Study of Atherosclerosis-Right Ventricle Study. Circulation 2011; 123: 2542-2551.

28 Barberà JA. Mechanisms of development of chronic obstructive pulmonary disease-associated pulmonary hypertension. Pulm Circ 2013; 3: 160-164.

29 Boerrigter BG, Bogaard HJ, Trip P, et al. Ventilatory and cardiocirculatory exercise profiles in COPD: the role of pulmonary hypertension. Chest 2012; 142: 1166-1174.

30 Sabit R, Bolton CE, Fraser AG, et al. Sub-clinical left and right ventricular dysfunction in patients with COPD. Respir Med 2010; 104: 1171-1178.

31 Mills NL, Miller JJ, Anand A, et al. Increased arterial stiffness in patients with chronic obstructive pulmonary disease: a mechanism for increased cardiovascular risk. Thorax 2008; 63: 306-311.

32 McAllister DA, Maclay JD, Mills NL, et al. Arterial stiffness is independently associated with emphysema severity in patients with chronic obstructive pulmonary disease. Am J Respir Crit Care Med 2007; 176: 1208-1214.

33 Maclay JD, McAllister DA, Mills NL, et al. Vascular dysfunction in chronic obstructive pulmonary disease. Am J Respir Crit Care Med 2009; 180: 513-520.

34 Mahmud A, Feely J. Effect of smoking on arterial stiffness and pulse pressure amplification. Hypertension 2003; 41: 183-187.

35 Giacomin E, Palmerini E, Ballo P, et al. Acute effects of caffeine and cigarette smoking on ventricular long-axis function in healthy subjects. Cardiovasc Ultrasound 2008; 6: 9.

36 Cottin V, Le Pavec J, Prévot G, et al. Pulmonary hypertension in patients with combined pulmonary fibrosis and emphysema syndrome. Eur Respir J 2010; 35: 105-111.

37 Holverda S, Rietema H, Bogaard HJ, et al. Acute effects of sildenafil on exercise pulmonary hemodynamics and capacity in patients with COPD. Pulm Pharmacol Ther 2008; 21: 558-564.

38 Blanco I, Gimeno E, Munoz PA, et al. Hemodynamic and gas exchange effects of sildenafil in patients with chronic obstructive pulmonary disease and pulmonary hypertension. Am J Respir Crit Care Med 2010; 181: $270-278$.

39 Blyth KG, Groenning BA, Mark PB, et al. NT-proBNP can be used to detect right ventricular systolic dysfunction in pulmonary hypertension. Eur Respir J 2007; 29: 737-744.

40 Mauritz GJ, Rizopoulos D, Groepenhoff H, et al. Usefulness of serial N-terminal pro-B-type natriuretic peptide measurements for determining prognosis in patients with pulmonary arterial hypertension. Am J Cardiol 2011; 108: $1645-1650$

41 Chang CL, Robinson SC, Mills GD, et al. Biochemical markers of cardiac dysfunction predict mortality in acute exacerbations of COPD. Thorax 2011; 66: 764-768.

42 Abroug F, Ouanes-Besbes L, Nciri N, et al. Association of left-heart dysfunction with severe exacerbation of chronic obstructive pulmonary disease: diagnostic performance of cardiac biomarkers. Am J Respir Crit Care Med 2006; 174: 990-996.

43 Høiseth AD, Omland T, Hagve TA, et al. NT-proBNP independently predicts long term mortality after acute exacerbation of COPD - a prospective cohort study. Respir Res 2012; 13: 97.

44 Ouanes I, Jalloul F, Ayed S, et al. N-terminal proB-type natriuretic peptide levels aid the diagnosis of left ventricular dysfunction in patients with severe acute exacerbations of chronic obstructive pulmonary disease and renal dysfunction. Respirology 2012; 17: 660-666.

45 Andersen CU, Mellemkjaer S, Nielsen-Kudsk JE, et al. Echocardiographic screening for pulmonary hypertension in stable COPD out-patients and NT-proBNP as a rule-out test. COPD 2012; 9: 505-512. 